\title{
Surface characterization and in vivo evaluation of laser sintered and machined implants followed by resorbable-blasting media process: A study in sheep
}

\author{
Michelle Bowers ${ }^{1}$, Daniel Yoo ${ }^{1}$, Charles Marin ${ }^{5}$, Luiz Gil ${ }^{2}$, Nour Shabaka ${ }^{3}$, Matt Goldstein ${ }^{1}$, Malvin Janal \\ ${ }^{4}$, Nick Tovar ${ }^{1}$, Ronaldo Hirata ${ }^{1}$, Estevam Bonfante ${ }^{1}$, Paulo Coelho ${ }^{1}$
}

\author{
${ }^{1}$ Department of Biomaterials and Biomimetics, New York University College of Dentistry, New York, USA \\ ${ }^{2}$ Department of Oral Surgery, Federal University of Santa Catarina, Florianópolis SC, Brazil \\ ${ }^{3}$ New York University Abu Dhabi, Abu Dhabi, United Arab Emirates \\ ${ }^{4}$ Department of Epidemiology, New York University College of Dentistry, New York, USA \\ ${ }^{5}$ Posgraduated program in Dentistry - Unigranrio University, School of Health Sciences, Duque de Caxias RJ, Brazil
}

Correspondence:

345 E 24th Street

10010. Biomaterials and Biomimetics

New York University

New York, NY, USA

rh1694@nyu.edu

\begin{abstract}
Bowers M, Yoo D, Marin C, Gil L, Shabaka N, Goldstein M, Janal M, Tovar N, Hirata R, Bonfante E, Coelho P. Surface characterization and in vivo evaluation of laser sintered and machined implants followed by resorbable-blasting media process: A study in sheep. Med Oral Patol Oral Cir Bucal. 2016 Mar 1;21 (2):e206-13.
\end{abstract}

Received: 17/07/2015 http://www.medicinaoral.com/medoralfree $01 / \mathrm{v} 21$ i2/medoralv21i2p206.pdf

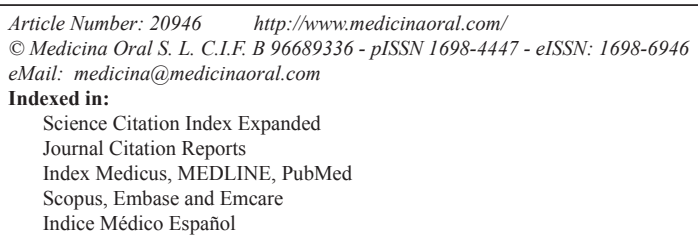

\begin{abstract}
Background: This study aimed to compare the histomorphometric and histological bone response to laser-sintered implants followed by resorbable-blasting media (RBM) process relative to standard machined/RBM surface treated implants.

Material and Methods: Six male sheep $(n=6)$ received 2 Ti-6Al-4V implants (1 per surface) in each side of the mandible for 6 weeks in vivo. The histomorphometric parameters bone-implant contact (BIC) and bone area fraction occupancy (BAFO) were evaluated.

Results: Optical interferometry revealed higher $\mathrm{S}_{\mathrm{a}}$ and $\mathrm{S}_{\mathrm{q}}$ values for the laser-sintered/RBM surface in relation to standard/RBM implants. No significant differences in BIC were observed between the two groups $(p>0.2)$, but significantly higher BAFO was observed for standard/RBM implants $(p<0.01)$.

Conclusions: The present study demonstrated that both surfaces were biocompatible and osseoconductive, and the combination of laser sintering and RBM has no advantage over the standard machined implants with subsequent RBM.
\end{abstract}

Key words: Dental implants, osseointegration, resorbable- blasting media, sheep, in vivo. 


\section{Introduction}

Current research has progressed towards implant design modifications and improvements of early host-implant tissue response and reducing treatment time (1). The potential benefits include faster oral rehabilitation from surgery to prosthetic restoration, and better performance in low quality bone regions compared to standard classic protocols (1-3). Multiple design alterations, initially implant surface surface, have been investigated and attempted to analyze their effects upon function and survival within the host (1-9).

The methodology for implant surface modification relies upon the fact that the initial interaction point of the implant body involves the host tissue which may have widespread implications in bone healing and intimate apposition with the device (8). Despite the large number of possible modifications, previous publications have generally reported rough surfaces (compared to smooth surfaces) and surface chemistry (Ca-P-based bioceramic additions over machined surfaces) may favorably impact the early host-implant response $(1,5,6,10-12)$. Implant surface texturing is typically completed during the post-fabrication process by milling to its desired macro-design (13-15). Surface roughness can be customized through its fabrication method, i.e. laser metal sintering (16-18).

Laser metal sintering is based on rapid prototyping, in which the compiled computer-aided design is constructed via a metal forming procedure with a highpower laser beam focused onto a metal powder bed and programmed for fusing particles to create a thin metal layer. The process continues until the progression of layer apposition completes the final 3D shape of the completed implant device (13-18). The final surface is marked as porous with functionally graded structures and an observed porosity gradient perpendicular to the implant long axis $(16,17,19)$. Controlled surface porosity and the core materials may be selected to fit the implant's intended purpose. In addition, the laser sintering process has been shown to produce a repeated porous pattern with an associated interconnected pore network, which may potentially improve overall osseointegration (13-18). The graded structure has also been claimed to decrease the discrepancy between the elastic modulus of titanium and that of the surrounding bone and form a favorable reduction in the interface stress (13-17). Laser sintering is suitable for a wide range of applications in the production of temporary or permanent implantable devices, particularly for designs required to construct an implant's structural and biological function (13).

In vivo evaluation of laser sintered implants compared with $\mathrm{AB} / \mathrm{AE}$ moderade rough surface showed higher values of BIC (bone-to-implant contact) and BAFO (bone area fraction occupied) parameters with statistical significance for the first week was found, similar values were found for 3 and 6 weeks. When torque to in- terface failure was measured higher values for sintered group for one and six weeks were found. Its advocated the implant micro-design achieved by laser-sintered may have provide an homogeneous and larger surface area for blood clot retention improving osseointegration process in its early stages (19). After the well described moderate rough surfaces (5) the Ca-P incorporation on the implant device (i.e. surface chemistry alteration) has also shown to improve osseoconductivity. Resorbable blasting media (RBM) is one of the available methods to integrate $\mathrm{Ca}-\mathrm{P}$ particles at a reduced amount on and into the implant surface. A previous study comparing five different implant systems showed that RBM surface presented similar bone-to-implant contact (BIC) when compared to others at 3 and 6 weeks, as well as maintain its bone elastic modulus and hardness values over the time (20). Despite the positive results in existing in vitro and in vivo data on laser metal sintering implants, subsequent surface treatment in these devices has not been yet assessed. The aim of present study is evaluate the effect of laser sintering followed by RBM process compared to standard machined implants, followed by a similar RBM process. The current hypothesis is the complex surface topography from the laser sintering combined to RBM would improve the overall histomorphometric parameters compared with the machined/RBM implants.

\section{Material and Methods}

The implants utilized in this study were Ti-6Al-4V screw type, tapered implants with $3.5 \mathrm{~mm}$ of diameter and $10 \mathrm{~mm}$ in length provided by the manufacturer (Adin, Afula, Israel). A total of 24 implants were used and divided into two groups according to fabrication process: standard machined implants with RBM blasted surface (Osseofix) (control) and laser-sintered implants that were also subsequently RBM blasted (experimental) ( $\mathrm{n}=12$ per group). Two additional implants were used for surface characterization.

- Surface Characterization

Surface characterization was carried out with three different methods. The first method involved scanning electron microscopy (SEM) (Zeiss, Oberkochen, Germany) that was performed at various magnifications under an acceleration voltage of $20 \mathrm{kV}$ to characterize the differences in surface topography within each group ( $\mathrm{n}=1$ per group).

The second method was employed to determine the roughness parameters by optical interferometry (IFM) (Zeiss, Oberkochen, Germany; PhaseView 2.5, Palaiseau, France). One implant of each surface was evaluated at the flat region of the implant cutting edges (five measurements per implant) in terms of $\mathrm{S}_{\mathrm{a}}$ (arithmetic average high deviation), $\mathrm{S}_{\mathrm{q}}$ (root mean square). A filter size of $100 \times 100 \mu \mathrm{m}^{2}$ was utilized. 
- Implantation Procedures

All animal experiments were conducted in accordance with the ethical approval The study was approved by the Ethics Committee for Animal Research at the E' cole Nationale Véetérinaire d'Alfort (Maisons-Alfort, Val-de-Marne, France). Six Finnish Dorset cross-bred sheep (each weighing approximately $70 \mathrm{~kg}$ ) were utilized for this study. The implants were inserted into the sheep mandible base of each animal. Prior to surgery, the mandibular regions were shaved using aseptic procedures. The animals were then monitored continuously for heart rate, oxygen saturation, respiratory rate, temperature, and tissue coloration prior to the complete shaving of the intended surgical site. The relevant adjacent areas were also accessed prior to the application of a povidone-iodine solution.

Monitoring was then transferred to an automated system and the animal draped aseptically. Anesthesia was induced with sodium pentothal $(15-20 \mathrm{mg} / \mathrm{kg})$ in Normasol solution in the jugular vein. Anesthesia was maintained with isoflurane (1.5-3\%) in $\mathrm{O}_{2} / \mathrm{N}_{2} \mathrm{O}(50 / 50)$. Preoperatively and postoperatively, $500 \mathrm{mg}$ cefazolin was administered intravenously. Throughout anesthesia, body temperature was maintained with a circulating hot water blanket placed underneath the sheep. Vital signs were intermittently monitored with electrocardiography, end-tidal $\mathrm{CO}_{2}$ and $\mathrm{SpO}_{2}$. The surgical procedure was performed at 6 weeks prior to euthanasia by means of a $10-\mathrm{cm}$ extraoral incision located $2 \mathrm{~cm}$ distally from the most distal position of the masseter. After mandibular bone exposure, the osteotomy was prepared using the drills provided by the manufacturer. Each animal received two implants of both control and experimental groups $(n=4$ implants per animal). Each side of the mandible receive one implant from each group, that were randomly placed in the sites in a proximal-to-distal order at 2-cm intervals from the adjacent implant centers.

The implant groups were interpolated as a function of implantation site to minimize site bias throughout the study. Postoperative antibiotic and anti-inflammatory medications included a single dose of benzylpenicillin benzathine $(20,000 \mathrm{IU} / \mathrm{kg})$ intramuscularly and ketoprofen $1 \%(1 \mathrm{~mL} / 5 \mathrm{~kg})$. The sheep were euthanized by anesthesia overdose, and the mandibles were retrieved by sharp dissection. The soft tissue was removed using surgical blades, and an initial clinical evaluation was performed to determine implant stability. If an implant was clinically unstable, it was excluded from the study. - Histological Preparation and Histomorphometry Each experimental implant group was processed for histological and histomorphometric evaluation via progressive dehydration in alcohol and methyl salicylate before final embedding in methylmethacrylate (MMA). Standard non-decalcified histological sections were prepared for each implant sample according to standard- ized methodology (21). The samples were first sectioned along the implant's long axis with a slow speed precision diamond saw (Isomet 2000, Buehler Ltd., Lake Bluff, IL, USA) as slices of $\sim 300 \mu \mathrm{m}$ thickness. Each tissue section was glued to an acrylic plate with a photolabile acrylate-based adhesive (Technovit 7210 VLC adhesive, Heraeus Kulzer GMBH, Wehrheim, Germany) prior to grinding and polishing under abundant water irrigation with a series of silicon carbide ( $\mathrm{SiC}$ ) abrasive papers (400, 600, 800, and 1200) (Metaserv 3000, Buehler Ltd., Lake Bluff, IL, USA) to a final thickness of $70 \mu \mathrm{m}$. The finalized sections were then stained with Stevenel's Blue and Van Gieson's Picro Fuschin (SVG) stains. Histologic observations and images were obtained using an automated slide scanning system and specialized computer software (Aperio Technologies, Vista, CA, USA). The bone-to-implant contact (BIC) was determined by means of a computer software (ImageJ, NIH, Bethesda, MD). The regions of bone-to-implant contact along the implant perimeter were subtracted from the total implant perimeter, and calculations were performed to determine the BIC. The bone area fraction occupied (BAFO) between threads in trabecular bone regions was determined by means of computer software (ImageJ, NIH, Bethesda, MD). The areas occupied by bone were subtracted from the total area between threads, and calculations were performed to determine the BAFO (reported in percentage values of bone area fraction occupied)

- Statistical Analysis

All histomorphometric data is presented as mean values with their corresponding 95\% confidence intervals (95\% CI), while the optical interferometry results were displayed with standard deviation (SD). The collected $\% \mathrm{BIC}$ and $\% \mathrm{BAFO}$ data were utilized to generate a general linear ANOVA model (NCSS LLC) with the level of significance set at $p<0.05$. The independent variable analyzed was the implant type.

\section{Results}

- Animal procedure

The surgical procedure surgical and post-operatory period was uneventful. No implants were excluded from this study after samples retrieval due to clinical instability.

- Surface Characterization

Scanning electron micrographs (SEM) of both implant surfaces at different magnifications showing the inclusion of RBM for standart/RBM and laser-sintered/ $\mathrm{RBM}$ are presented in figure 1. Three-dimensional IFM reconstructions $(100 \mu \mathrm{m}$ x $100 \mu \mathrm{m})$ showing remarkable differences between surface topography of control and experimental groups (Fig. 2A,B). Values of $\mathrm{S}_{\mathrm{a}}$ and $\mathrm{S}_{\mathrm{q}}$ are presented in figure $2 \mathrm{C}$. Control and experimental groups presented statistical difference for both param- 

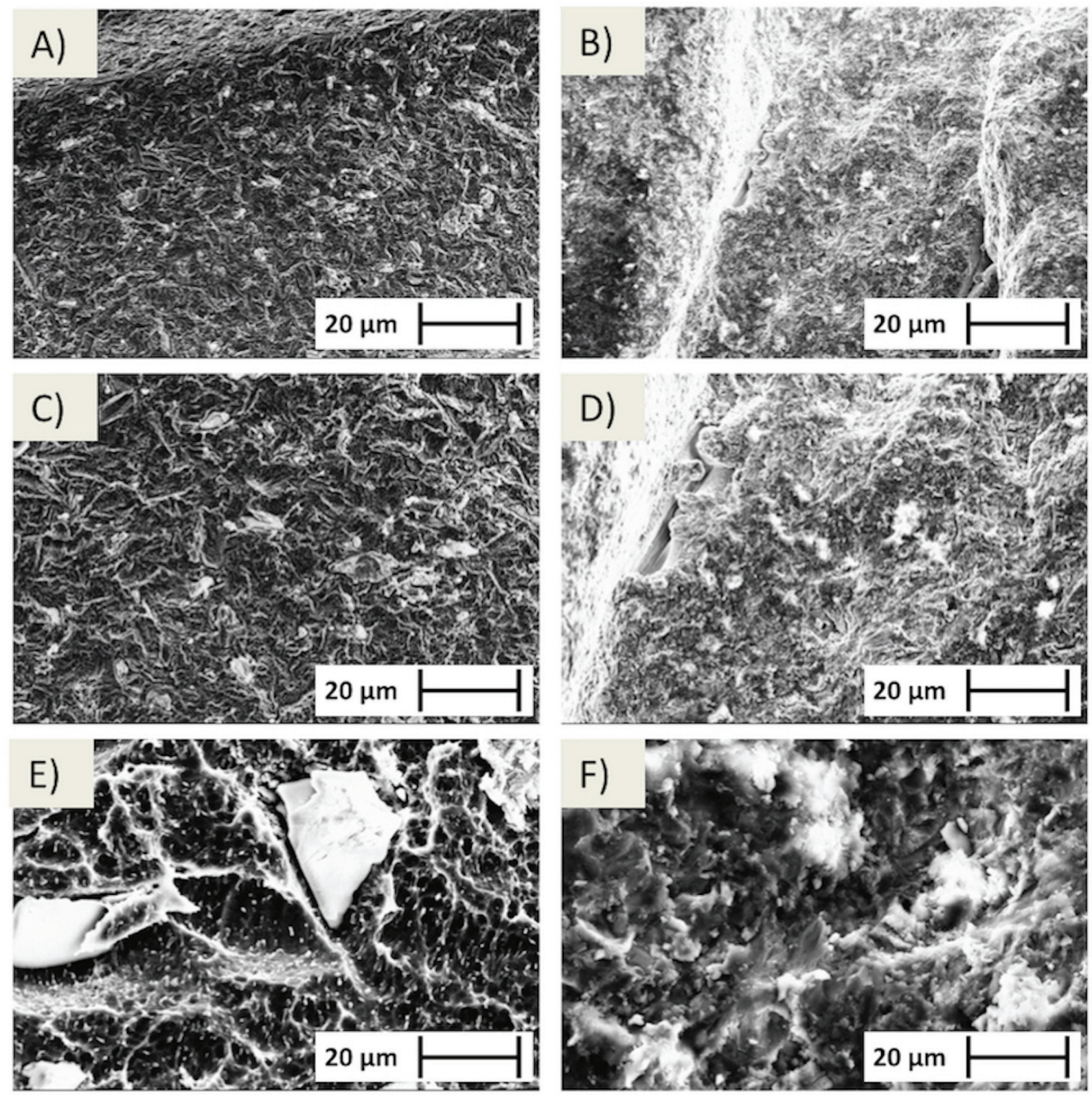

Fig. 1. SEM images of standard (A, C, and E) and laser-sintered (B, D, and F) obtained under progressively higher magnification. Note RBM media inclusion within surface for both groups.

eters measured $\left(\mathrm{S}_{\mathrm{a}}\right.$ and $\left.\mathrm{S}_{\mathrm{q}}\right)$ with higher values for experimental group (laser sintered/RBM) $(p<0.05)$.

- Histomorphometric Parameters

No significant differences for BIC were observed between the standard/RBM and laser-sintered/RBM implant groups ( $p>0.2$; Fig. 3A). However, the same pattern was not observed for BAFO, where standard/RBM implants presented significantly higher bone formation over that of laser-sintered/RBM implants ( $p<0.01$; Fig. 3B).

- General Histological Observations

Nondecalcified sample processing revealed intimate bone contact with all implant surfaces at cortical and trabecular bone regions. For both surfaces osteonic structures were observed in close contact of implant surface (arrows) demonstrating mature and well organized bone structure even in healing chambers formed by osteotomy diameter and implant macro-design. Bone formation was observed in contact with the implant away from the osteotomy line showing the intramembranous-like bone formation initiating from the implant surface after 6 weeks in vivo (asterisk) (Fig. 4).

\section{Discussion}

Chemical and topographical surface modifications have earned extensive interest due to promising results shown in in vitro and in vivo relative to their commercial pred- 

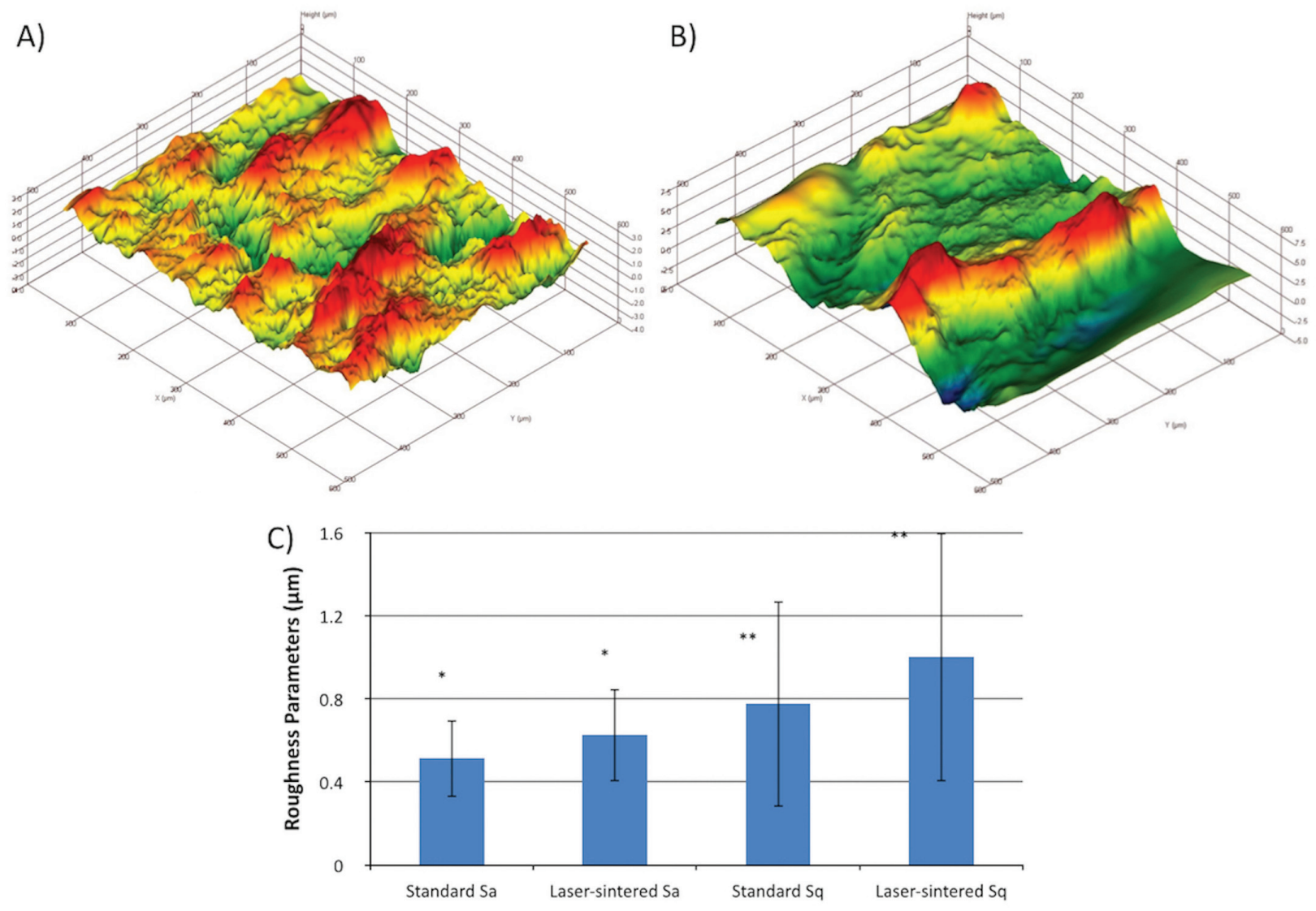

Fig. 2. (A, B) Representative IFM reconstruction images (filter size of $100 \times 100 \mu \mathrm{m}^{2}$ ) of the standard and laser-sintered implants, respectively. (C) Statistical summary (mean $\pm \mathrm{SD}$ ) for surface roughness parameters, $\mathrm{S}_{\mathrm{a}}$ and $\mathrm{S}_{\mathrm{q}}$, for each implant group. Note that the asterisks represent statistically homogenous groups.
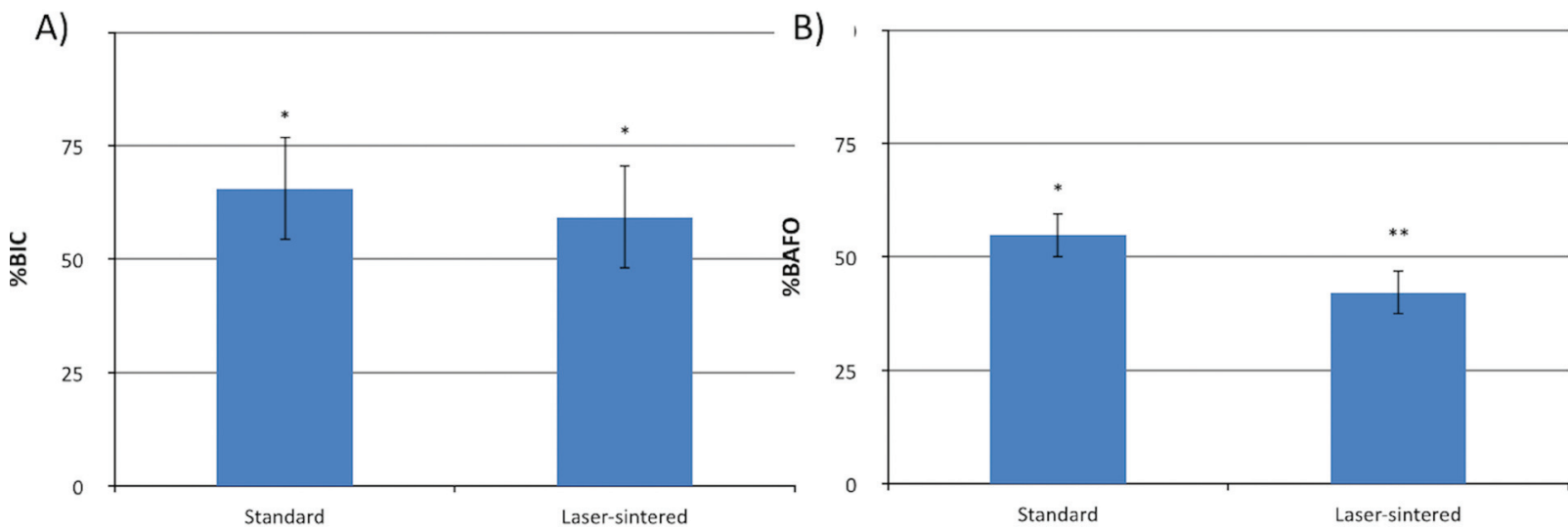

Fig. 3. Statistical summary (mean $\pm 95 \% \mathrm{CI}$ ) for $\% \mathrm{BIC}$ and $\% \mathrm{BAFO}$ for standard and laser-sintered implants considering surface treatment at 6 weeks in vivo. Note that the asterisks represent statistically homogenous groups.

ecessors $(1,5,6,22-31)$. The implant surface modification has evolved from as-machined, smooth surfaces to microscopically moderately roughened surfaces that have shown to enhance bone healing after the placement of implants $(1,10,32)$. Laser sintered implants are classified as moderately rough range, proving to be an effective method to produce an osseoconductive surface $(19,33$ 37). \{Witek, 2012 \#21\}\{Witek, 2012 \#21\}Subsequent surface chemistry modifications such as the incorporation of bioactive ceramics have long been the focus of investigations as a positive factor for improved early bone healing. However, considering that surface chem- 

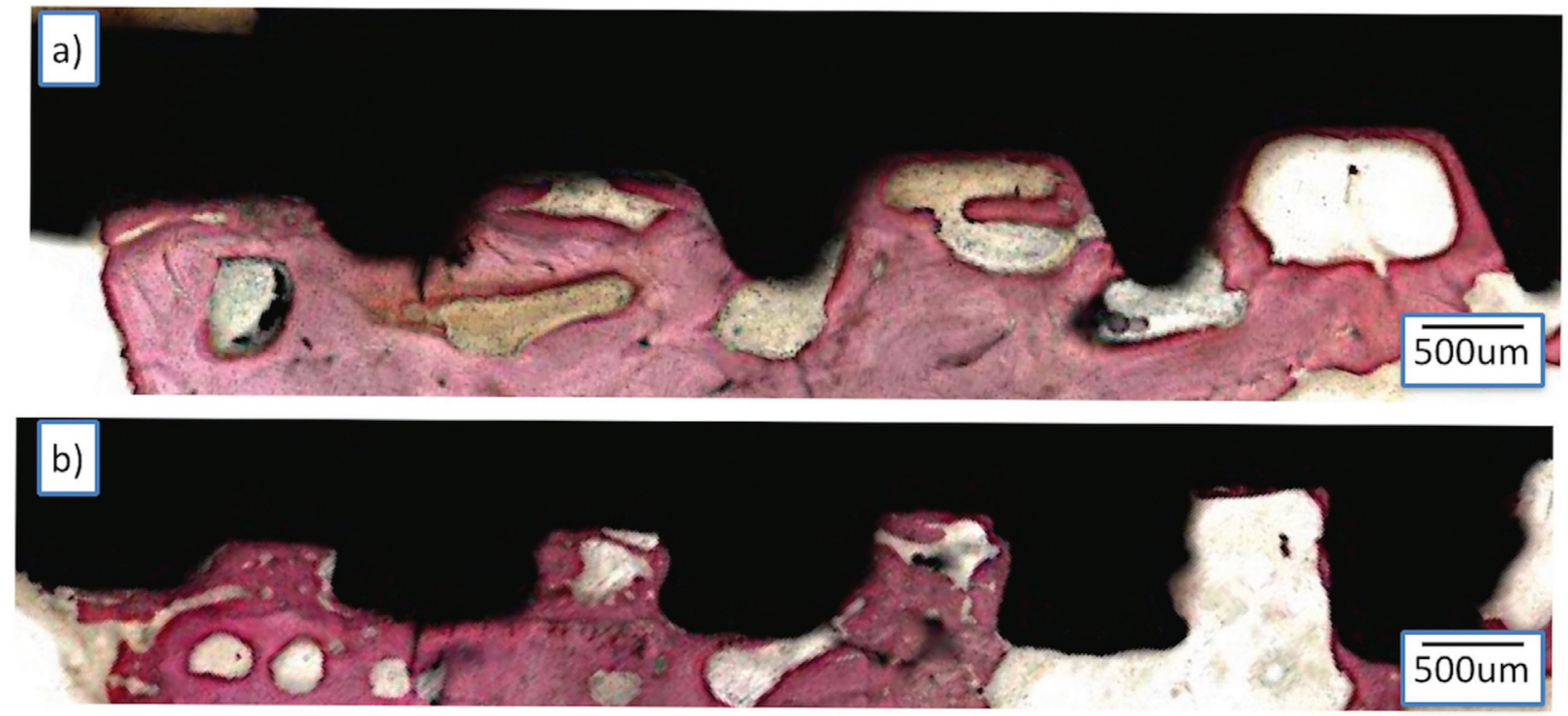

Fig. 4. Histological sections showing bone healing around the standard (A) and laser-sintered (B) implant groups at 6 weeks post-implantation. Bars represent $200 \mu \mathrm{m}$.

istry modifications typically involve changes in surface topography (25), it is still unclear whether resulting topography changes alone and/or the combination with chemical modifications leads to improved osseointegration (38).

The chemical modification of the surface after laser sintering, as the Ca-P incorporation after RBM process performed in the present study, could hypothetically improve histomorphometric results when compared to standard/RBM implants. Although $\mathrm{S}_{\mathrm{a}}$ values reached statistically difference between standard/RBM $(0.51 \pm 0.19$ $\mu \mathrm{m})$ and laser-sintered/RBM $(0.78 \pm 0.49 \mu \mathrm{m})$ groups, both are classified as moderate rough surfaces. The data of present study showed an decrease of roughness parameters $\left(\mathrm{S}_{\mathrm{a}}\right.$ and $\left.\mathrm{S}_{\mathrm{q}}\right)$ when laser-sintered implants are processed by means of RBM, producing minimally rough surface. However, multiple processing variables appear to provide an effect on the finished surface topography of laser-sintered implants and probably on their osteogenic properties, i.e. the power rating of the laser, beam focus diameter, scanning speed, average particle size of the initiating material powder, atmospheric conditions, and others (39). Also, besides the sintering protocol, the combination of laser sintering and RBM could have affected overall $\mathrm{S}_{\mathrm{a}}$ values. Marin et al. (40) evaluated $\mathrm{S}_{\mathrm{a}}$ for an $\mathrm{AB} / \mathrm{AE}, \mathrm{RBM}$ /acid etched (RBMa) and a hybrid implant $(\mathrm{AB} / \mathrm{AE}+\mathrm{RBMa}) \cdot \mathrm{AB} / \mathrm{AE}$ implants showed higher $\mathrm{S}_{\mathrm{a}}$ when compared to others, with the hybrid device reaching an intermediate value.

For Histomorphometric parameters evaluated in this study, only BAFO values were significantly different at 6 weeks in vivo with the standard/RBM group presenting higher overall values compared to those of
laser-sintered/RBM implants. Previous studies have hypothesized that the three-dimensional surface configuration of the laser-sintered implant potentially produced a larger exposed surface area during the early wound healing cascade along with increased blood clot retention compared to the control implant group (19). BIC results showed no significant differences between the experimental and control groups. As such, the present scope of this study did not involve multiple and earlier time-points, which may have excluded the detection of early bone responses within the host.

Current literature have also reported no significant differences between groups by 6 weeks post-implantation as early bone healing may no longer be the dominant process in play at this point $(19,20)$. Since secondary stability of the implanted device is one of the primary goals of design research, BIC and other related interfacial statistics may be the more vital histomorphometric category. Thus, despite the observed increase in BAFO within the standard/RBM group compared with lasersintered/RBM group, the lack of statistically significant differences for BIC values could indicate the need for additional comparison studies between these two groups at early time-points in order to include the host early bone response. The general results from this study show that both implants investigated are biocompatible and osseoconductive, resulting in a similar bone-healing pattern at cortical and trabecular bone in close contact with the implant surface. The rationale of testing the association between laser sintering and RBM surface was to provide a rougher surface due to laser sintering, when compared to standard machined process, combined with the presence of Ca-P achieved with subsequent RBM 
treatment. However, our proposed hypothesis, when laser-sintered/RBM implants would enhance the overall histomorphometric parameters in comparison to the standard/RBM implant surface was not accepted due to the absence of significant differences in BIC values and negative effect on BAFO results.

The present study is limited in scope from a temporal perspective and requires additional investigation for the proper elucidation of laser-sintered/RBM implant materials and their effects within a sheep model. In addition to earlier time-points for observing the initial host wound and bone healing response, future studies with variations in specific processing parameters and surface physic-chemical characterization are warranted. These investigations would also provide substantial information by biomechanical (torque testing) (19), nanomechanical (nanoindentation) (41), and even the underlying genetic/molecular processes (bone markers) (42) corresponding to the observed tissue effects. Despite the utilization of several animal species, including sheep, in implant materials testing, variations in the innate remodeling rate must be considered when conducting in vivo studies of this nature (43).

\section{Conclusion}

Based on the results observed in our investigation, both surfaces were biocompatible and osseoconductive, and the combination of laser sintering and RBM has no advantage over the standard machined implants with subsequent RBM.

\section{References}

1. Coelho PG, Granjeiro JM, Romanos GE, Suzuki M, Silva NR, Cardaropoli G, et al. Basic research methods and current trends of dental implant surfaces. Journal of biomedical materials research Part B, Applied biomaterials. 2009;88:579-96.

2. Jimbo R, Ono D, Hirakawa Y, Odatsu T, Tanaka T, Sawase T. Accelerated photo-induced hydrophilicity promotes osseointegration: an animal study. Clinical implant dentistry and related research. 2011;13:79-85.

3. Jimbo R, Sawase T, Baba K, Kurogi T, Shibata Y, Atsuta M. Enhanced initial cell responses to chemically modified anodized titanium. Clinical implant dentistry and related research. 2008;10:55-61.

4. Albrektsson T, Gottlow J, Meirelles L, Ostman PO, Rocci A, Sennerby L. Survival of NobelDirect implants: an analysis of 550 consecutively placed implants at 18 different clinical centers. Clinical implant dentistry and related research. 2007;9:65-70.

5. Albrektsson T, Wennerberg A. Oral implant surfaces: Part 1--review focusing on topographic and chemical properties of different surfaces and in vivo responses to them. The International journal of prosthodontics. 2004;17:536-43.

6. Albrektsson T, Wennerberg A. Oral implant surfaces: Part 2--review focusing on clinical knowledge of different surfaces. The International journal of prosthodontics. 2004;17:544-64.

7. Coelho PG, Granato R, Marin C, Teixeira HS, Suzuki M, Valverde GB, et al. The effect of different implant macrogeometries and surface treatment in early biomechanical fixation: an experimental study in dogs. Journal of the mechanical behavior of biomedical materials. 2011;4:1974-81.
8. Jimbo R, Sawase T, Shibata Y, Hirata K, Hishikawa Y, Tanaka $\mathrm{Y}$, et al. Enhanced osseointegration by the chemotactic activity of plasma fibronectin for cellular fibronectin positive cells. Biomaterials. 2007;28:3469-77.

9. Yoo D, Tovar N, Jimbo R, Marin C, Anchieta RB, Machado LS, et al. Increased osseointegration effect of bone morphogenetic protein 2 on dental implants: an in vivo study. J Biomed Mater Res A. 2014;102:1921-7.

10. Wennerberg A, Albrektsson T. On implant surfaces: a review of current knowledge and opinions. The International journal of oral \& maxillofacial implants. 2010;25:63-74.

11. Bonfante EA, Witek L, Tovar N, Suzuki M, Marin C, Granato R, et al. Physicochemical Characterization and In Vivo Evaluation of Amorphous and Partially Crystalline Calcium Phosphate Coatings Fabricated on Ti-6Al-4V Implants by the Plasma Spray Method. International journal of biomaterials. 2012;2012:603826.

12. Coelho PG, Granato R, Marin C, Jimbo R, Lin S, Witek L, et al. Effect of Si addition on Ca- and P-impregnated implant surfaces with nanometer-scale roughness: an experimental study in dogs. Clinical oral implants research. 2012;23:373-8.

13. Balla VK, Bodhak S, Bose S, Bandyopadhyay A. Porous tantalum structures for bone implants: fabrication, mechanical and in vitro biological properties. Acta biomaterialia. 2010;6:3349-59.

14. Goodridge RD, Wood DJ, Ohtsuki C, Dalgarno KW. Biological evaluation of an apatite-mullite glass-ceramic produced via selective laser sintering. Acta biomaterialia. 2007;3:221-31.

15. Porter NL, Pilliar RM, Grynpas MD. Fabrication of porous calcium polyphosphate implants by solid freeform fabrication: a study of processing parameters and in vitro degradation characteristics. $\mathbf{J}$ Biomed Mater Res. 2001;56:504-15.

16. Chua CK, Leong KF, Tan KH, Wiria FE, Cheah CM. Development of tissue scaffolds using selective laser sintering of polyvinyl alcohol/hydroxyapatite biocomposite for craniofacial and joint defects. Journal of materials science Materials in medicine. 2004;15:1113-21. 17. Li JP, de Wijn JR, Van Blitterswijk CA, de Groot K. Porous Ti6A14V scaffold directly fabricating by rapid prototyping: preparation and in vitro experiment. Biomaterials. 2006;27:1223-35.

18. Williams JM, Adewunmi A, Schek RM, Flanagan CL, Krebsbach $\mathrm{PH}$, Feinberg SE, et al. Bone tissue engineering using polycaprolactone scaffolds fabricated via selective laser sintering. Biomaterials. 2005;26:4817-27.

19. Witek L, Marin C, Granato R, Bonfante EA, Campos F, Bisinotto $\mathrm{J}$, et al. Characterization and in vivo evaluation of laser sintered dental endosseous implants in dogs. Journal of biomedical materials research Part B, Applied biomaterials. 2012;100:1566-73.

20. Jimbo R, Anchieta R, Baldassarri M, Granato R, Marin C, Teixeira HS, et al. Histomorphometry and bone mechanical property evolution around different implant systems at early healing stages: an experimental study in dogs. Implant dentistry. 2013;22:596-603.

21. Donath K, Breuner G. A method for the study of undecalcified bones and teeth with attached soft tissues. The Sage-Schliff (sawing and grinding) technique. Journal of oral pathology. 1982;11:318-26. 22. Coelho PG, Cardaropoli G, Suzuki M, Lemons JE. Early healing of nanothickness bioceramic coatings on dental implants. An experimental study in dogs. Journal of biomedical materials research Part B, Applied biomaterials. 2009;88:387-93.

23. Coelho PG, Marin C, Granato R, Suzuki M. Clinical DeviceRelated Article Histomorphologic Analysis of 30 Plateau Root Form Implants Retrieved After 8 to 13 Years in Function. A Human Retrieval Study. J Biomed Mater Res B. 2009;91B:975-9.

24. Coelho PG, Suzuki M, Guimaraes MV, Marin C, Granato R, Gil $\mathrm{JN}$, et al. Early bone healing around different implant bulk designs and surgical techniques: A study in dogs. Clinical implant dentistry and related research. 2010;12:202-8.

25. Ehrenfest DMD, Coelho PG, Kang BS, Sul YT, Albrektsson T. Classification of osseointegrated implant surfaces: materials, chemistry and topography. Trends Biotechnol. 2010;28:198-206. 
26. Granato R, Marin C, Suzuki M, Gil JN, Janal MN, Coelho PG. Biomechanical and histomorphometric evaluation of a thin ion beam bioceramic deposition on plateau root form implants: an experimental study in dogs. J Biomed Mater Res B Appl Biomater. 2009;90:396-403.

27. Kang BS, Sul YT, Oh SJ, Lee HJ, Albrektsson T. XPS, AES and SEM analysis of recent dental implants. Acta biomaterialia. 2009;5:2222-9.

28. Marin C, Granato R, Suzuki M, Gil JN, Piattelli A, Coelho PG. Removal torque and histomorphometric evaluation of bioceramic grit-blasted/acid-etched and dual acid-etched implant surfaces: an experimental study in dogs. Journal of periodontology. 2008;79:1942-9.

29. Mendes VC, Moineddin R, Davies JE. The effect of discrete calcium phosphate nanocrystals on bone-bonding to titanium surfaces. Biomaterials. 2007;28:4748-55.

30. Mendes VC, Moineddin R, Davies JE. Discrete calcium phosphate nanocrystalline deposition enhances osteoconduction on titanium-based implant surfaces. Journal of biomedical materials research Part A. 2009;90:577-85.

31. Coelho PG, Lemons JE. Physico/chemical characterization and in vivo evaluation of nanothickness bioceramic depositions on alumina-blasted/acid-etched Ti-6Al-4V implant surfaces. Journal of biomedical materials research Part A. 2009;90:351-61.

32. Wennerberg A, Albrektsson T. Effects of titanium surface topography on bone integration: a systematic review. Clinical oral implants research. 2009;20Suppl 4:172-84.

33. Mangano C, De Rosa A, Desiderio V, d'Aquino R, Piattelli A, De Francesco F, et al. The osteoblastic differentiation of dental pulp stem cells and bone formation on different titanium surface textures. Biomaterials. 2010;31:3543-51.

34. Mangano C, Mangano F, Shibli JA, Luongo G, De Franco M, Briguglio F, et al. Prospective clinical evaluation of 201 direct laser metal forming implants: results from a 1-year multicenter study. Lasers in medical science. 2012;27:181-9.

35. Mangano C, Piattelli A, Raspanti M, Mangano F, Cassoni A, Iezzi G, et al. Scanning electron microscopy (SEM) and X-ray dispersive spectrometry evaluation of direct laser metal sintering surface and human bone interface: a case series. Lasers in medical science. 2011;26:133-8.

36. Shibli JA, Mangano C, D'Avila S, Piattelli A, Pecora GE, Mangano F, et al. Influence of direct laser fabrication implant topography on type IV bone: a histomorphometric study in humans. Journal of biomedical materials research Part A. 2010;93:607-14.

37. Traini T, Mangano C, Sammons RL, Mangano F, Macchi A, Piattelli A. Direct laser metal sintering as a new approach to fabrication of an isoelastic functionally graded material for manufacture of porous titanium dental implants. Dental materials : official publication of the Academy of Dental Materials. 2008;24:1525-33.

38. Wennerberg A, Albrektsson T. Structural influence from calcium phosphate coatings and its possible effect on enhanced bone integration. Acta odontologica Scandinavica. 2009;67:333-40.

39. Hollander DA, von Walter M, Wirtz T, Sellei R, Schmidt-Rohlfing B, Paar O, et al. Structural, mechanical and in vitro characterization of individually structured Ti-6Al-4V produced by direct laser forming. Biomaterials. 2006;27:955-63.

40. Marin C, Bonfante EA, Jeong R, Granato R, Giro G, Suzuki $\mathrm{M}$, et al. Histologic and Biomechanical Evaluation of Two Resorbable Blasting Media (RBM) Implant Surfaces at Early Implantation Times. The Journal of oral implantology. 2013;39:445-53.

41. Baldassarri M, Bonfante E, Suzuki M, Marin C, Granato R, Tovar N, et al. Mechanical properties of human bone surrounding plateau root form implants retrieved after 0.3-24 years of function. Journal of biomedical materials research Part B, Applied biomaterials. 2012;100:2015-21.

42. Coelho PG, Freire JN, Granato R, Marin C, Bonfante EA, Gil JN, et al. Bone mineral apposition rates at early implantation times around differently prepared titanium surfaces: a study in beagle dogs. The International journal of oral \& maxillofacial implants. 2011;26:63-9.
43. Bloebaum RD, Ota DT, Skedros JG, Mantas JP. Comparison of human and canine external femoral morphologies in the context of total hip replacement. Journal of biomedical materials research. 1993;27:1149-59.

\section{Conflict of Interest}

The authors state no conflict of interest. 